Int. J. Dev. Biol. 49: 161-171 (2005)

doi: $10.1387 / \mathrm{ijdb} .041937 \mathrm{sc}$

\title{
Neural crest derivatives in ocular and periocular structures
}

\author{
SOPHIE CREUZET* , CHRISTINE VINCENT and GÉRARD COULY \\ Institut d'Embryologie Cellulaire et Moléculaire du CNRS et du Collège de France, UMR 7128, Nogent-sur-Marne cedex, France
}

\begin{abstract}
In vertebrates, the eye is an ectodermal compound structure associating neurectodermal and placodal anlagen. In addition, it benefits early on from a mesenchymal ectoderm-derived component, the neural crest. In this respect, the construction of chimeras between quail and chick has been a turning point, instrumental in appraising the contribution of the cephalic neural crest to the development of ocular and periocular structures. Given the variety of crest derivatives underscored in the developing eye, this study illustrates the fascinating ability of this unique structure to finely adapt its differentiation to microenvironmental cues. This analysis of neural crest cell contribution to ocular development emphasizes their paramount role to design the anterior segment of the eye, supply refracting media and contribute to the homeostasy of the anterior optic chamber.
\end{abstract}

KEY WORDS: neural crest, quail-chick chimera, cell migration, limbus, cornea, iridial muscle, ciliary corpus, Sclemm's canal, eyelid, nictitating membrane

\section{Introduction}

Vertebrates differ from the other chordate subphylla by the considerable expansion of their brain and sense organs. Those structures have benefited from a crucial asset in evolutionary transition, the neural crest, that has endowed cephalic structures with skeletal protection and vascularization. In vertebrate embryos, neural crest transiently consists in a neural fold bulging at the margin of the neural epithelium in the early neurula. While the neuroepithelium engages its dorsal closure to form the neural tube, neural crest cells detache and become mesenchymal. Their migrating properties lead them to spread and pervade different regions of the embryo where they yield a broad range of derivatives (from myofibroblast, melanocyte, endocrine cell, neurones, glial cells to cartilage and bone). Investigations carried in the avian embryos by the mean of the quail-chick chimeras were instrumental in mapping their fate and emphasized the major role of neural crest in head development (Le Douarin, 1982; Le Douarin and Kalcheim, 1999; Le Douarin et al., 2004).

At the cephalic level, neural crest cells provide the forepole of vertebrate embryo with diverse mesenchymal derivatives that form the mesectoderm (Kastschenko, 1888; Platt, 1893) and concur to the emergence of the head by giving rise to the craniofacial connective, dermal and skeletal tissues (Le Lièvre, 1974; Le Lièvre and Le Douarin, 1975; Noden, 1983; Couly et al., 1993).

In the early neurula, previous fate maps performed the quailchick chimera system have demonstrated that the association of the ectoderm-derived components of the eye results from the convergence of a medioventral retinal neurectoblast with the dorsolateral ectoderm of the optic placode first identified lateral to the diencephalic neural fold (Couly and Le Douarin, 1987). The neuroectodermal origin of the eye lies at first in the diencephalic neural plate, tightly interposed between the posthypophysis and telencephalic vesicle anlagen, in their medial and lateral aspects, respectively (Fig. 1A; Couly et al., 1985). The presumptive territory of the retina accompanies the expansion of the diencephalic vesicle, which grows out laterally until it faces the superficial ectoderm of the optic placode (Fig. 1C). Concurrently with the thickening of the ectoderm responsible for the differentiation of the lens, the invagination of the diencephalic vesicle leads to the delineation of an optic cup that will forms the optic vesicle (OV), the margin of which encompasses the lenticular vesicle.

While the optic ectodermal and neurectodermal components benefit precociously from a mesenchymal environment of mesoderm origin (see Fig. 1B), mesodermal cell fate is consistent with the derivatives usually encountered in the rest of the head; these include myogenic precursors of external ocular muscles as well as endothelial cells of blood vessels, that all take part to the periocular structures at the end of the first week (Couly et al., 1992).

Abbreviations used in this paper: Cal, calvarium; CoEn, coronary endothelium; CoEp, cor neal epithelium, Di, diencephalon; IRE, inner retinal epithelium; Is, isthmus; Ms, mesencephalon; NC, neural crest; ORE, outer retinal epithelium; OV, optic vesicle; SEM, scanning electron micrograph.

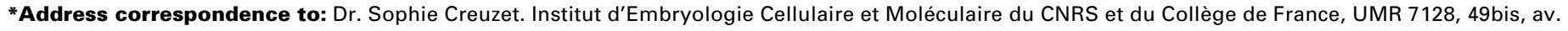
de la Belle Gabrielle, F-94736 Nogent-sur-Marne cedex, France. Fax: +33-1-4873-4377. sophie.creuzet@college-de-france.fr
} 

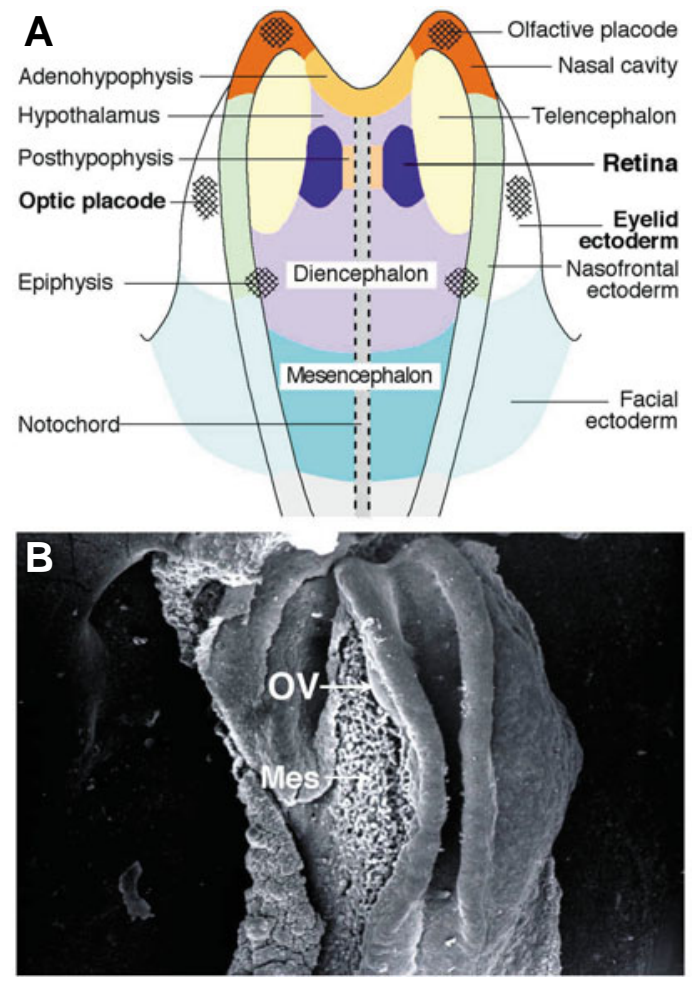

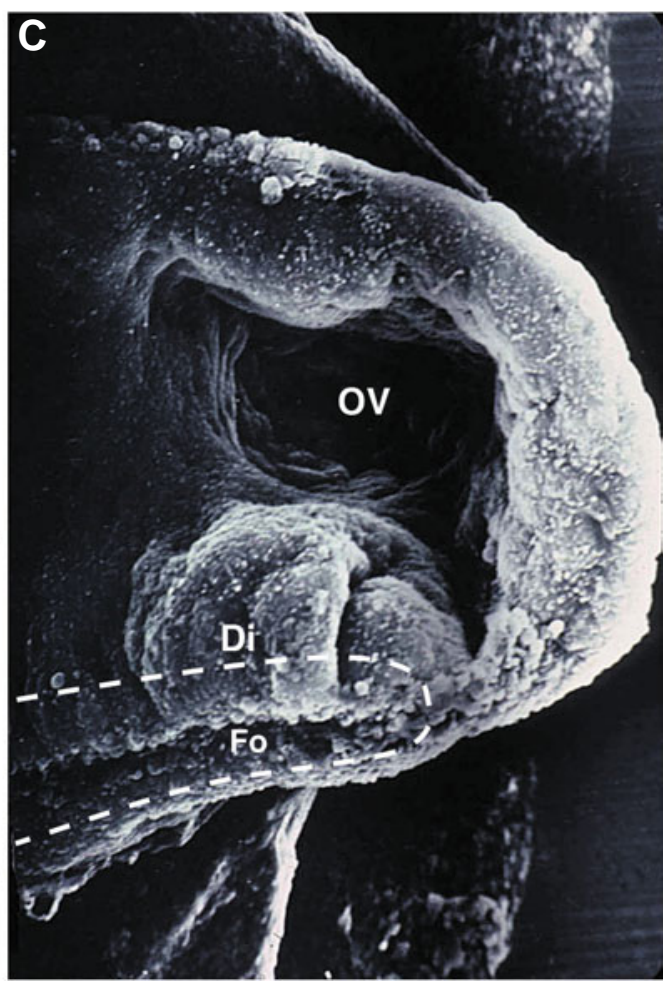

Fig. 1. Ectodermal origins of the ocular anlage. (A) Fate map of the anterior neural plate and neural fold in chick embryo at the 3 somite stage (ss) as established by Le Douarin and coworkers (Couly and Le Douarin, 1987). The neuroectodermal territory fated to give rise to the retina (violet) lies in the diencephalic floor plate (pink), interposed between the presumptive telencephalic neuroepithelium (yellow) and the posthypophysis (beige). The optic placode (grey lattice) at the origin of the lens is lateral to the anterior diencephalic non-crest cell producing neural fold and is surrounded by the presumptive eyelid ectoderm (white). (B) Dorsal view of a scanning electron micrograph (SEM) of the 3ss chick head in which the lateral ectoderm has been extirpated thus showing the lateral aspect of the outgrowing optic vesicle (OV) surrounded by the cephalic mesoderm (Mes). (C) Inner aspect of the lefthand half of a $7 s s$-chick embryo sagittally cut; at this stage, the neuroectoderm of the optic vesicle expands laterally at the transverse level of the diencephalic floor plate (Di) to reach and contact the ectodermal anlage of the optic placode. Note the position of the foregut endoderm (Fo; dotted line).

Considering the involvment of the ectoderm-derived mesenchyme araising from cephalic neural crest, its contribution to ocular structures has been essentially uncovered from the midseventies by the pionneer users of the quail-chick marker system (Le Lièvre, 1978; Johnston et al., 1979). However, some aspects relating to the origin of either pigmented mesenchymal cells or myogenic precursors still remain to be clarified. The ocular derivatives, that are re-evaluated hereafter, are to a large extent illustrative of the crest plasticity completely restricted to the cephalic domain (see Le Douarin et al., 2004, for a review). In this respect, recent data have provided molecular evidence of the tight relationship that has linked the emergence of the cephalic neural crest and eye field expansion during the evolution of the chordate phylum (Ciesielka et al., 2004). It turns out that, unlike in invertebrates, p120catenin, though being highly conserved, is tightly associated to vertebrate eye development since its depletion severely affects eye growth and craniofacial skeletogenesis. However, though a great deal of bibliography primarily concerns developmental and evolutionary aspects of genetic networks involved in ectodermal and neurectodermal patterning (for reviews, see Fernald, 2000; Gehring, 2002; Arendt, 2003), little is known about the signalling pathways required for the specification of the crest-derived ocular mesenchyme.

In the present study, we have revisited and illustrated the contribution of the neural crest cells to the intra- and peri-ocular structures using quail-chick chimeras. This paper discusses the mesectodermal input as a contribution to optic physiology and tries to provide a brief review of the molecular pathways the neural crest relies on for its participation to the developing eye.

\section{Results}

\section{Early optic colonization by cephalic neural crest cells}

In our experiments, the diencephalic, mesencephalic and/or metencephalic neural folds were dissected out from a 5-6ss quail embryo as a source of neural crest cells and subjected to homotopic transplantation into a stage-matched chick (Fig. 2 $B, E)$. The migration of neural crest cells expanding from the transplant was first traced in QCPN-stained whole-mount preparations $24 \mathrm{~h}$ after grafting (embryonic day $2-\mathrm{E} 2$ ). The quail neural crest cells arising from the diencephalic neural fold spread over the prosencephalic vesicles, filled up the nasofrontal bud and colonized the rostral half of the OV (Fig. $2 \mathrm{~A}-\mathrm{C}$ ). Concurrently, the mesencephalic neural crest cells migrated bilaterally towards the facial processes including the nasolateral and maxillomandibular buds (Fig. 2 D-F). Neural crest cells arising from the metencephalic level migrated massively into the first branchial arch (BA1) and also along the superficial ectoderm to reach the latero-posterior and latero-ventral aspects of the eye, thus colonizing the pedoncular zone (not shown). These migration streams completely invaded the optic region therefore encompassed the OV.

From E3 to E4, neural crest quail cells detected on serial sections pervaded the ocular structure through a superficial pathway under the ectoderm and also colonized the periocular domain by migrating along the wall of the diencephalon until they reached the optic stalk (Fig. 3 A,B). Thus, crest-derived mesenchymal cells replenished the interface between the OV, the stalk and the central nervous system (Fig. 3 C,D). 


\section{Localization of neural crest cells around the optic vesicle}

At E5.5, in the posterior segment of the forming OV, neural crest-derived cells accumulated in contact with the outer epithelium of the OV, where they differentiated into pericytes lining the blood vessels of the choroid membrane. At this level, neural crest cells also gave rise to pigmented cells. An outer tunica of quail cells encompassing the choroid membrane formed aggregates which prefigured the formation of the sclerotic cartilaginous mantle (Fig. 3E).

At the equatorial level of the OV, neural crest-derived cells adopted a loose mesenchymal organization and mixed with mesodermal cells of host origin.

In the anterior segment of the OV, neural crest cells were arranged in three domains that differed according to the tissues they were associated with. i) A subset of grafted-derived cells accumulated in close contact with the outer retinal epithelium fated to form the sclero-corneal limbus (Fig. 3E). ii) A monolayer of crestderived cells moved into the space between the superficial ectoderm (also designated corneal epithelium) and the lens epithelium, lining the inner side of the corneal epithelium; it will be designated as the corneal endothelium (Fig. 3G). At E7, the formation of the corneal endothelium which delineates the anterior optic chamber was completed and it was entirely made up of neural crest-derived quail cells. iii) Surrounding the corneal endothelium and the future anterior chamber of the eye, quail cells accumulated thus delimiting the chamber angle (Fig. 3 E,F). At this level, graft-derived cells interposed between the superficial ectoderm and the margin of the OV where the outer and inner epithelia of the OV abutted and superficially overlapped the lens epithelium (Fig. 3F). At E7, these crest-derived cells formed the ciliary corpus (Fig. $3 \mathrm{H}$ ) in which large vascular lumens were visible. From E9 onward, the lateral border of the OV grew centripetally to form the iris (Fig. 4 A-C) in which pigment cells differentiated.

\section{Neural crest derivatives in intra- and peri-ocular structures}

At E12, crest-derived cells had invaded the superficial aspect of the iris to form the iridial stroma. At the irido-corneal angle they formed the ciliary muscle (Fig. 4 A-F). Those cells which were associated with the iridial epithelia were fated to form the iridial musculature (Fig. 5D). They exhibited both smooth and striated muscular phenotypes as shown by the accumulation of the smooth-muscle actin protein (SMA; Fig. 5F) and of transcripts of the skeletal muscle myogenic factor, MyoD (Fig. 5E). Moreover, a subset of these cells expressed the antigen recognized by the 13F4 Mab (Fig. 5G) which labels the differentiating muscle cells (Rong et al., 1987). Aggregates of quail cells derived from the ciliary corpus formed the ciliary muscle (Fig. 4F). These ciliary muscle-forming cells were contiguous to those, also of quail origin, that lined the sinus cilio-scleralis (Fig. 4F). QCPN-labelled mesenchymal cells were intimately associated with the wrinkled pigmented epithelium of the ciliary corpus (Fig. 5A) and massively adopted a pigment cell fate around the whole OV (Fig. 5 A-C). These cells therefore were not derived from the pigmented OV epithelium, as previously proposed by Barrio-Asensio and coworkers (Barrio-Asensio et al., 1999; Barrio-Asensio et al., 2002).
Fig. 2. Cephalic neural crest cell migration converging towards the optic vesicle. (A) Scanning electron micrograph (SEM) showing the forepole of a 5 ss chick embryo. The of neural crest (NC) territory (delineated with dotted lines) subjected for remplacement by its quail counterpart obtained from a stage-matched chick involves the posterior diencephalic level as schematically represented in (B). (C) Whole-mount immunodetection of quail neural crest cells which have basically colonized the anterior half of the optic vesicle at E2, one day after grafting (arrows). (D) The same SEM as in $A$ in which the mesencephalic and anterior metencephalic neural fold is delineated (dotted lines). (E) Scheme representing the interspecific transfer of this territory from a 5 ss quail donor embryo to a stage-matched chick host. (F) Wholemount detection of the quail neural crest cells that have spread from the graft into the host environment at E2.5; laterally migrating neural crestderived cells have massively moved (arrows) around the ocular region by
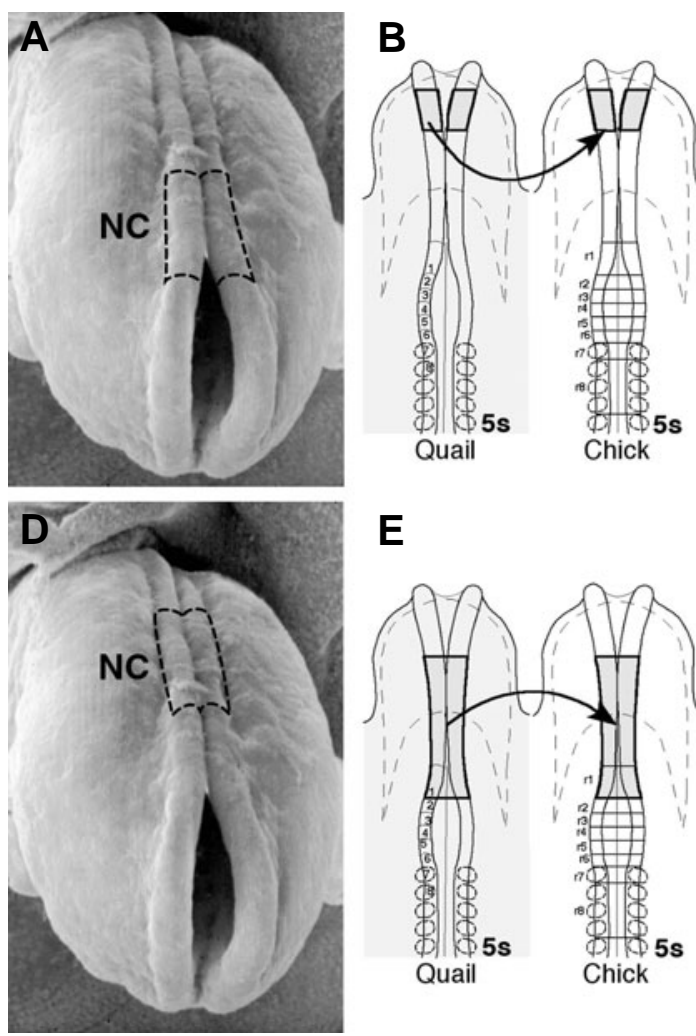

E

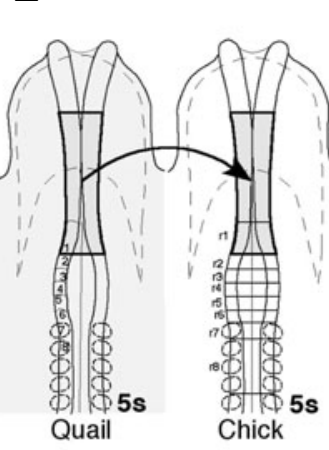

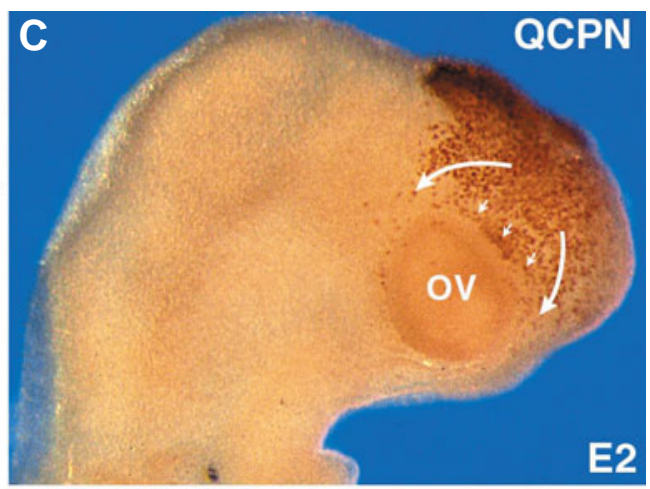

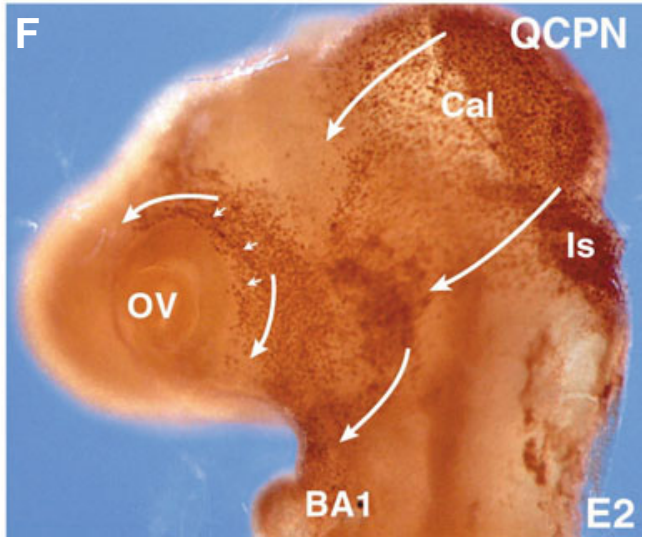

encompassing the posterior three quarters of the optic vesicle (OV). Note that a large part of graft-derived cells which are destined to form the calvarium (Cal) remains dorsally located thus covering the posterior mesencephalon and the isthmus (Is). 

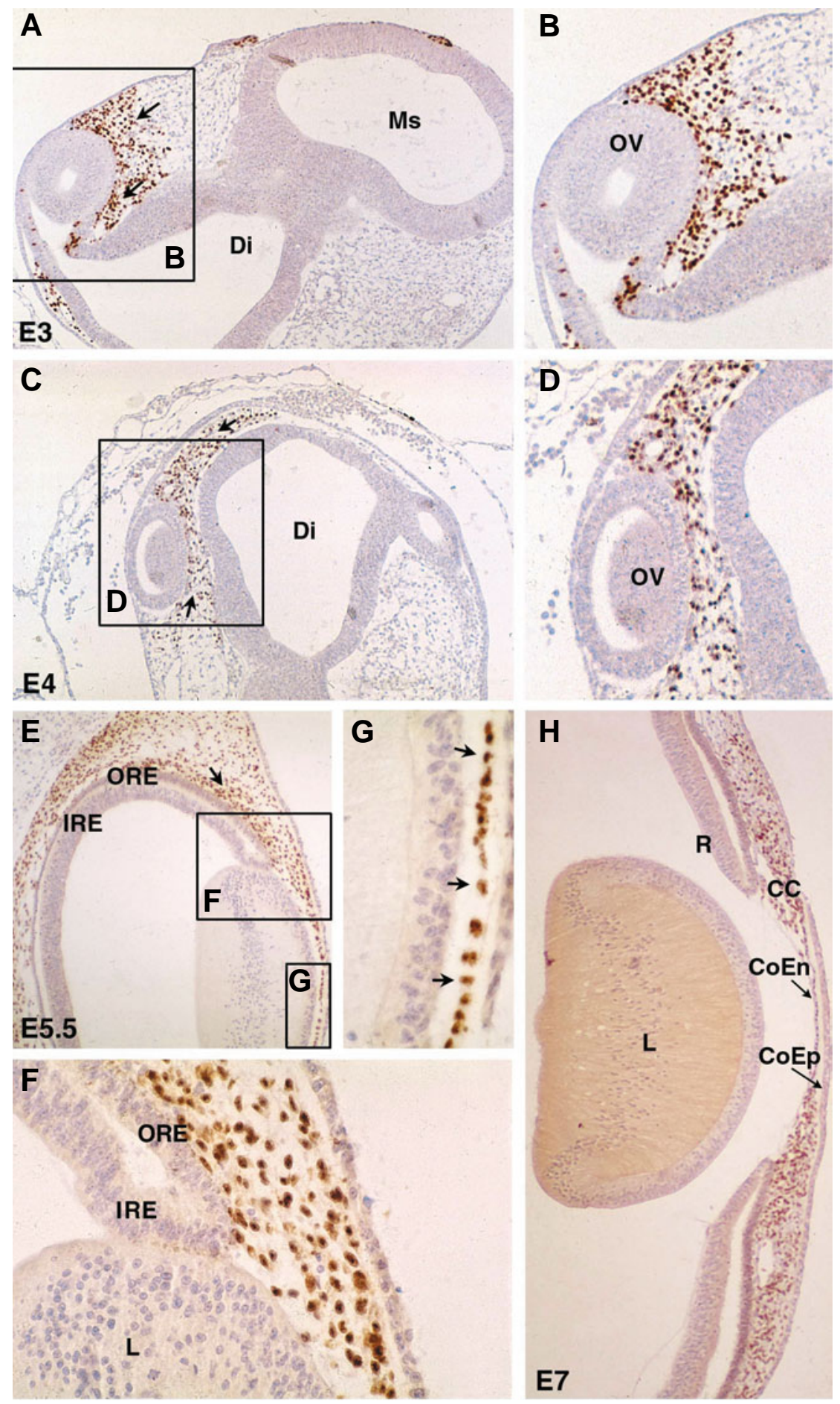

Covering the anterior optic chamber, the cornea had developed into a chimeric structure. Its overlaying ectoderm of host origin formed the corneal epithelium proper (Fig. 4G), whereas the underlying mesenchyme as well as the inner epithelium, referred to as the corneal endothelium, were of quail origin (Fig. $4 \mathrm{H}-\mathrm{J}$ ). In contrast, cells forming the lens and deriving from the host's superficial cephalic ectoderm were exclusively made up of chick cells (Fig. 4K).

The posterior segment of the eyeballs was tightly associated with neural crest-derived cells lying in contact with the external part of the
Fig. 3. Localization of neural crest cells around the developing optic vesicle. (A) At E3, quail neural crest cells immunodetected with QCPN Mab have migrated from the transplant implanted at the mesencephalic level (Ms) and primarily form the perioptic mesenchyme. (B) Higher magnification showing that crest-derived cells are intimately associated with the ectoderm of the optic vesicle (OV). (C) At E4, the quail crest-derived mesenchyme is evenly distributed around the presumptive eyeball filling the space between the optic and diencephalic (Di) ectoderms. (D) Close-up picture from framed area in C. (E) At E5.5, while the optic cup neuroectoderm has evolved into a double-layered structure consisting of the outer and inner retinal epithelia (ORE and IRE, respectively), neural crestderived cells are accumulated in the anterior segment of the eye (at the margin of the optic cup where ORE and IRE are linked) and form the chamber angle (F). (G) Laterally, quail cells which have expanded from the anterior chamber, occupy the interface between the lenticular epithelium and the overlaying ectoderm both of host origin; they give rise to the corneal endothelium (arrows). (H) At E7, in the anterior segment closed by the lens $(L)$, the retinal margin $(R)$ and the corneal epithelium (CoEp), neural crest-derived cells form the ciliary corpus (CC) and the corneal endothelium (CoEn) thus lining the inner aspect of the anterior optic chamber.

pigmented retina and forming the choroid membrane where they differentiated into pericytes and pigment cells (Fig. $4 \mathrm{~L}, \mathrm{~N}, \mathrm{O}$ ). The cells located in contact with the choroid membrane, were chondrified and formed the sclerotic cartilages (Fig. $4 \mathrm{~L}, \mathrm{~N}$ ). In the vicinity of the latter, osteogenic foci forming the sclerotic ossicles and periosteum, all around the equatorial zone, were entirely made up of quail cells (Fig. 4M).

In the periocular region, a subset of neural crest-derived cells which had migrated along the superficial ectoderm (see Fig. 3A,B) contributed to the expansion of ectodermal appendages fated to form both the upper and lower eyelids and the nictitating membrane (Fig. 4P). In the latter, the mesenchyme was exclusively made up of quail cells, as well as in the upper eyelid (Fig. $4 \mathrm{~N}, \mathrm{~V}, \mathrm{~W}$ ). In the lower eyelid, neural crest-derived cells gave rise to myoblasts for the palpebral muscles (Fig. 4 Q-S) which are responsible for eyelid motility in post-natal birds (Fig. $4 \mathrm{~T}, \mathrm{U}$ ). Eyelid muscle cells consisted of smooth-muscle type as evidenced by SMA expression up to $\mathrm{E} 12$ (Fig. $5 \mathrm{H}, \mathrm{I})$. From that stage on, they were also stained with the $13 \mathrm{~F} 4 \mathrm{Mab}$ which labels both smooth and striated muscles (Fig. $5 \mathrm{~J}, \mathrm{~K}$ )

\section{Discussion}

The origin of the ocular mesenchyme has long been a matter of debate tending to decipher the respective contribution of the cephalic mesoderm and mesectoderm to the eye and periocular structures. In this respect, construction of chimeras between quail and chick 
embryos has provided a reliable approach to trace and unravel the long-term involvement of crest-derived cells in eye developement. The present paper aims at reviewing and illustrating the contribution of cephalic neural crest cells and the derivatives they give rise to the intra- and extra-ocular structures.

From E2, the chick ocular region gains a vast mesenchymal supply of neural crest cells which originate from the posterior diencephalon, the mesencephalon and the metencephalon (corresponding to the two first rhombomeres, r1r2). This territory corresponds to the cephalic domain of the neural fold that yields the formation of the facial skeleton (Couly et al., 2002; Le Douarin et al., 2004 for a review). The optic cup is then invaded by the diencephalic crest cells for its anterior and lateral aspects, by the mesencephalic ones for its dorsal and medial parts and by the metencephalic crest cells for its latero-ventral region. However, converging to the OV, these different streams of crest cell migration extensively overlap, precluding the accurate drawing of a fate map of the presumptive eye colonization by neural crest cells.

Concurrently with the flux of crest cells reaching the optic cup, a minor but essential progression of mesodermal cells occurs towards the interface between the superficial ectoderm and the lenticular vesicle leading to the differentiation of macrophage-like cells (Hay, 1980; Garcia-Porrero et al., 1984; Cuardos et al., 1991). These cells clean up the debris released by the apoptotic events associated with lens morphogenesis, a prerequisite for the deposition of a primary corneal stroma permissive for neural crest cell migration into the lensectoderm interspace (Hay, 1980). At the posterior segment, neural crest and mesodermal cells mix to synergize the development of a functional vasculature as well as the extra-ocular musculature. By replacing chick cephalic neural primordium by their quail counterparts, Le Lièvre and Le Douarin (Le Lièvre and Le Douarin, 1975; Le Lièvre, 1978) first recorded the presence of Feulgen-positive nucleoli in the connective tissues of the extraocular muscles while myofibers derived from the host mesoderm (see Couly et al., 1992). In addition, the musculo-connective wall of ocular vessels and pericytes of the choroid membrane derived from the cephalic neural crest (Le Lièvre, 1978; Johnston et al., 1979; Etchevers et al., 1999). Furthermore, a subset of neural crest-derived cells in the choroid membrane exhibited a pigmented phenotype.

The mesectodermal differentiation at this level was further documented by demonstrating that the neural crest is responsible for the skeletal orbital and sclerotic structures housing the posterior segments of the developing eyeballs (Le Lièvre and Le Douarin, 1975; Le Lièvre, 1978). That the neural crest yields a skeletal protection for ocular structures is confirmed by experiments in which the cephalic neural crest is surgically extirpated at 5-6ss. In this case, embryos develop without sclera and, therefore, exhibit deformed oblong eyes, due to the absence of a cartilaginous nest (Couly et al., 2002). Surprisingly, when performed earlier in 3-4ss chick embryo, neural crest extirpation results in cyclopia, the severity of which appears to be stage-dependant (Etchevers etal., 1999; and our own unpublished data). Such a phenotype likely points out to a transient crest-dependent molecular requirement that has not been identified so far. Taken together, these data emphasize the inability of the cephalic mesoderm to substitute for the neural crest cells in building mesectodermal skeletal elements of any kind (belonging to either neurocranium or viscerocranium).

Furthermore, a great deal of regulation can occur within the cephalic neural crest domain to yield sclerotic structures since only a third of this territory, whatever its level of origin, can yield a normal sclera (Couly et al., 2002). Additionally, as for the facial skeleton, ocular structures turn out to be sensitive to ectopic Hox gene expression to an extent that depends on the transfected gene: Hoxa2 expression prevents sclera formation, Hoxb4 alike, while Hoxa3 hinders crest cell differentiation into skeletogenic and pericytic phenotypes all around the developing eye (Creuzet et al., 2002). Thus, deficits resulting from Hox gene expression in the forehead territory - as a consequence of either heterotopic transplantation or transfection - accounts for axial difference in the potential of neural crest cells to participate in posterior ocular structures along the rostrocaudal axis. Deficits associated with Hoxgene expression also affect the other crest-derived structures of the developing eye, as recently confirmed (Lwigale et al., 2004).

Once the contribution of neural crest cells to the posterior segment of the eye established, most attention was paid to the anterior segment of the eye due to its importance in the optic physiology and its histological complexity. In the seminal study from Johnston and coworkers (Johnston et al., 1979), interspecific combinations involving either cephalic mesoderm or neural crest ascertained the wide participation of mesectodermal cells at this level. In the anterior segment, two main areas of neural crest differentiation can be distinguished: an ocular one comprising the iris, the ciliary process and the cornea that delineate the anterior optic chamber and a periocular one including the nictitating membrane and eyelids (see Table 1).

Taken together, these data conspicuously point to a key contribution of the neural crest cells in endowing the anterior segment with refractive structures and media. First, neural crest cells ensure a mechanistic refracting function through the synthesis of a collagen matrix by the crest-derived keratocytes of the corneal stroma. Second, neural crest cells concur to the homeostasy of the anterior chamber by being associated with the production of the acqueous humor from the ciliary body, by collecting the anterior chamber fluid that bathes and nourishes the lens epithelium and by draining it out towards Schlemm's canal. Third, neural crest cells by giving rise to sclerotic ossicles exert tensile forces upon the intraocular fluid pressure and constraint the proper corneal curvature (Coulombre and Coulombre, 1958), thus directing light to the retina. These views are in accordance with data that have dissected the role of PaxGin ocular epithelial structures in conjunction with the development of ocular mesenchyme in mammals (see, Cvekl and Tamm, 2004, for a review).

At the edge of both anterior and posterior eye segments, the transition of neural crest fates does not occur by a clear-cut boundary but through an intermediate zone corresponding to the limbic area. Linking the margin of the sclerotic to the irido-corneal angle, the limbus receives a massive contribution of neural crest cells among which both pigment cells and smooth-actin expressing cells are recorded. In this respect, this area displays an noteworthy transition whereby crest-derived cells progressively diverge from both pigmented and pericytic phenotypes in the choroid membrane towards either pigmented cells for ciliary process, pericytes for Schlemm's canal, smooth muscle cells in ciliary muscle or striated muscle cells in iris. This observation relates to another problem as to whether the pigmented mesenchymal cells, abundantly found both in ciliary process and ciliary corpus from stage $\mathrm{HH} 37$, are of mesenchymal or of epithelial origin. It was of interest to determine whether the peripheral retina would be able to generate pigmented 

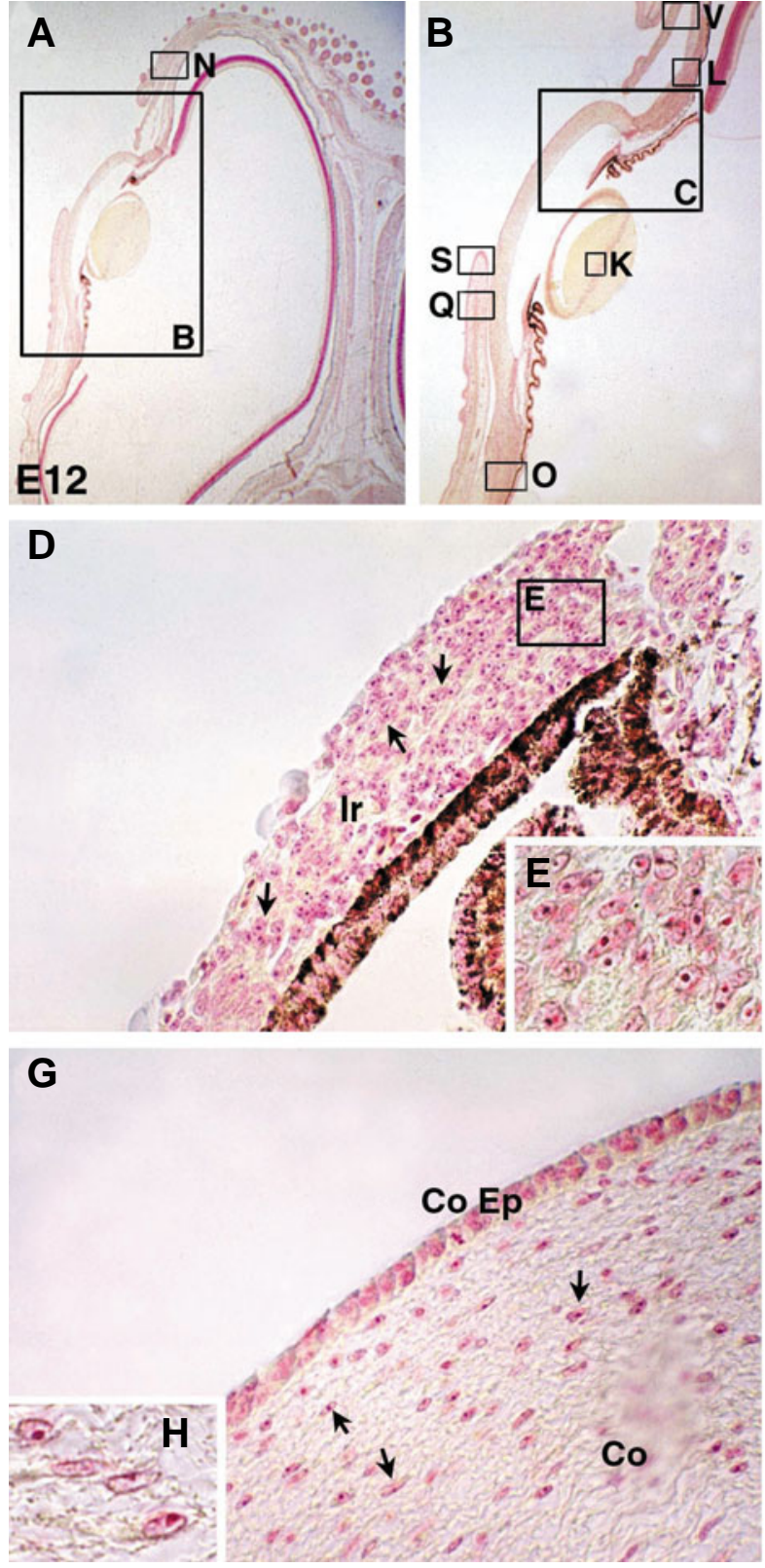
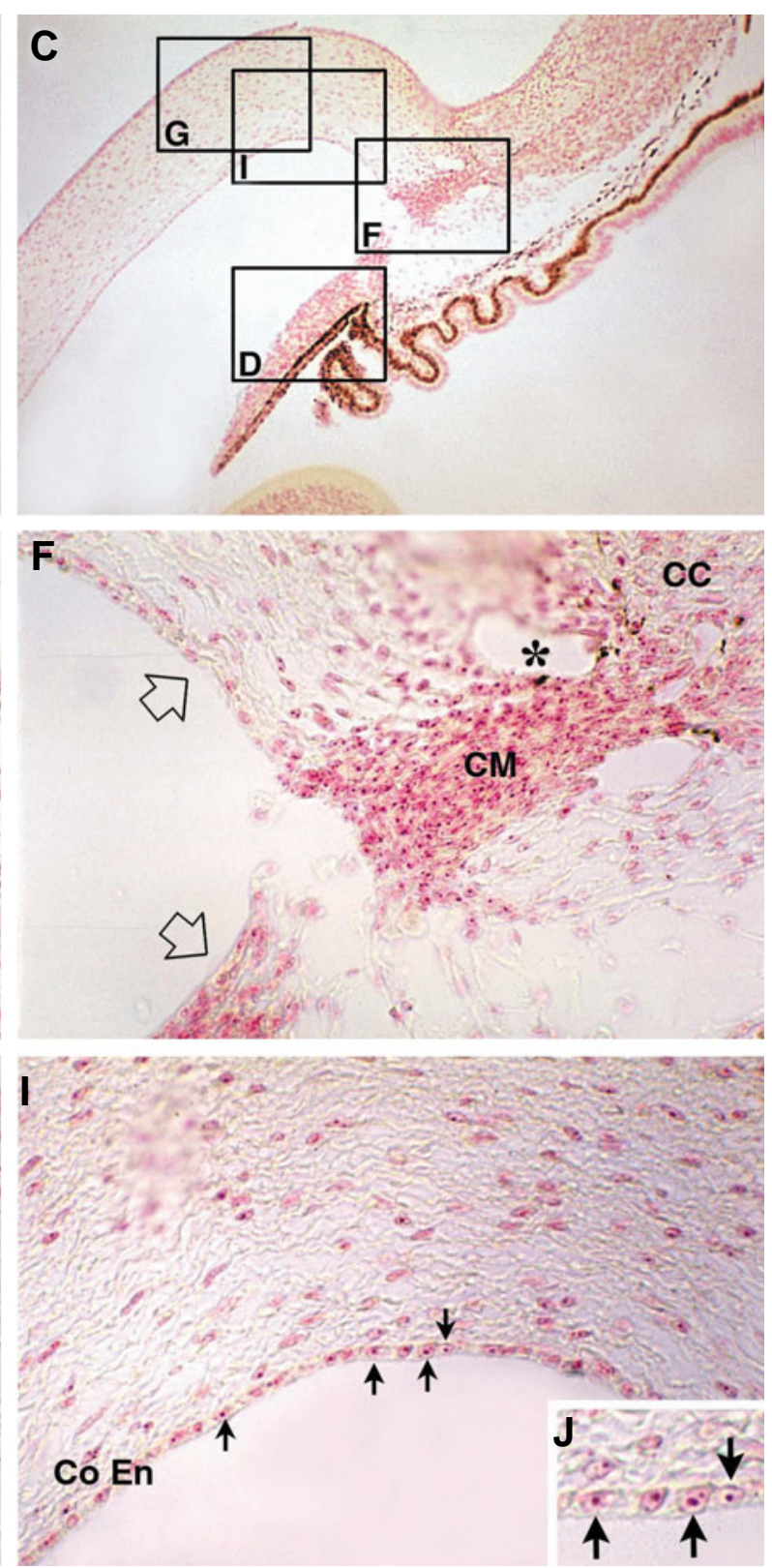

Fig. 4. Neural crest contribution to the morphogenesis of the ocular and periocular apparatus. (A) Feulgen-stained section of a chimeric eye taken from an E12 chick that has been engrafted with quail diencephalic and mesencephalic neural crest at E1.5. (B) Enlargement from A focused on the anterior optic chamber and (C) a close-up picture of the irido-corneal angle. (D) The iridial stroma (Ir) made up of quail neural crest cells (arrows) has accompanied the expansion of the host-derived pigmented epithelium from the retina; (E) quail specific labelling of the stromal cell nucleolus. (F) In the irido-corneal angle (open arrows), quail cells from the ciliary corpus have aggregated to form the ciliary muscle (CM) and line the endothelium of Schlemm's canal $(*)$. Note the presence of pigmented cells. $(\mathbf{G}, \mathbf{I})$ In the cornea, while the outer epithelium (CoEp) is of host origin, the stromal cells (Co; arrows; G) as well as the inner epithelial cells (CoEn; arrows; I) are derived from the engrafted quail neural crest, as illustrated in (H,J) respectively. (K) In contrast, lens fibers are exclusively of host origin. (L) At the edge of the cornea and the periocular structures, quail cells form the sclero-corneal limbus (ScCl), linking the corneal stroma (Co) to the sclerotic cartilage (Sc). (M) In the vicinity of the latter, osteogenic foci corresponding to sclerotic ossicles have differentiated from crest cells (arrows) as well as periosteum. (N,P) Covering the nasal portion of the eye, the nictitating membrane (arrows in P) has a crest-derived mesenchyme (Ni; arrows in N). (0) Interposed between the sclera and the pigmented retinal epithelium of donor and host origin respectively, quail mesectodermal cells give rise to pericytes and pigment cells in the choroid membrane (Ch). (P) The ectodermal folds which externally line the upper and lower aspects of eyeballs are filled with crest-derived mesenchymes; $(\mathbf{Q}, \mathbf{R})$ in the lower eyelid, the forming palpebral muscle (PaM in Q) consists of neural crest-derived cells (arrows in R) with a platismal insertion at the margin of the lid (S). (T,U) In hatched animals, the lower eyelid is the only motile one responsible for eye shutting. (V) Relative positions of the lower eyelid and the nictitating membrane (Ni) in which mesenchymal cells are of crest origin (W). 

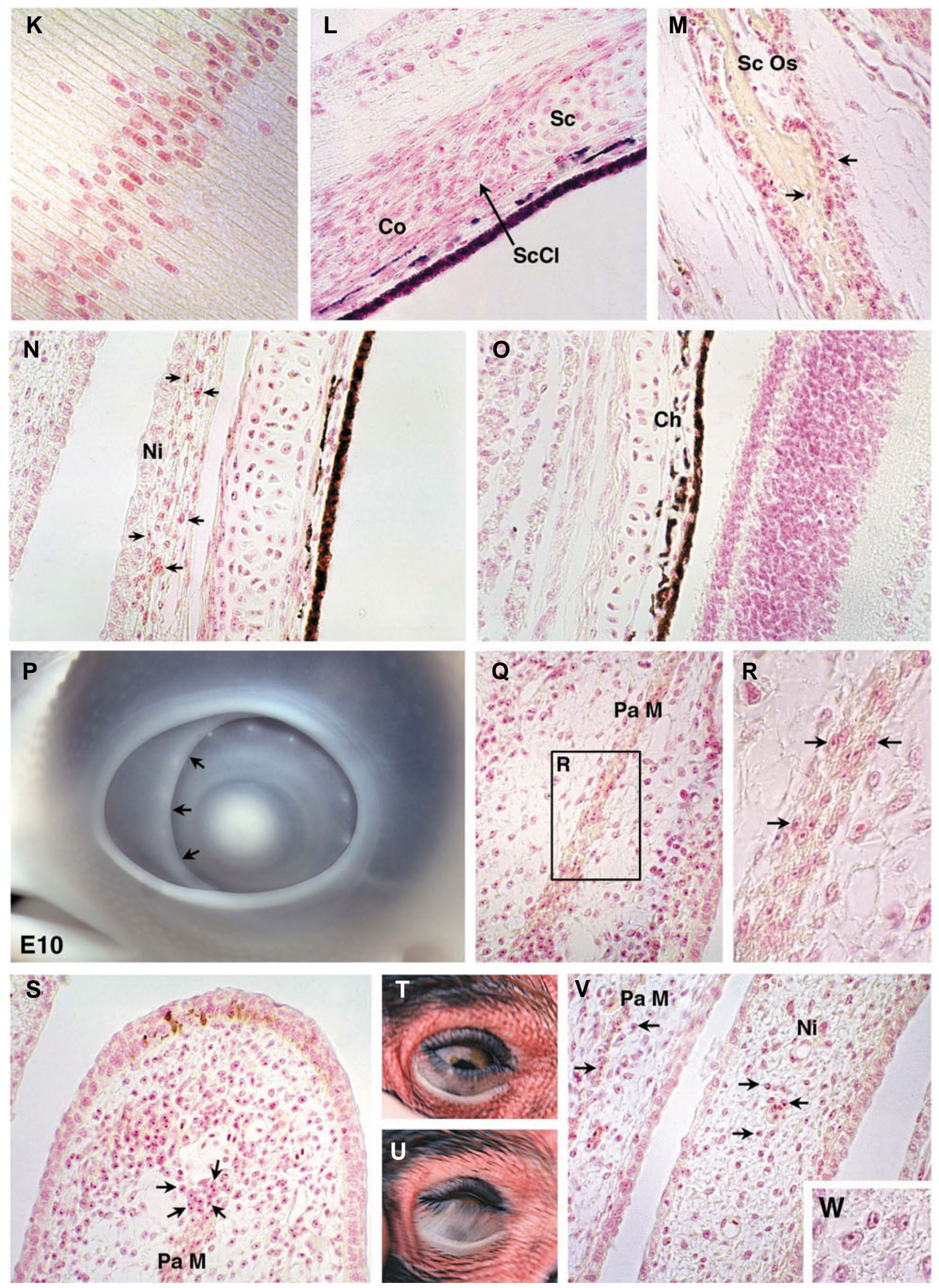


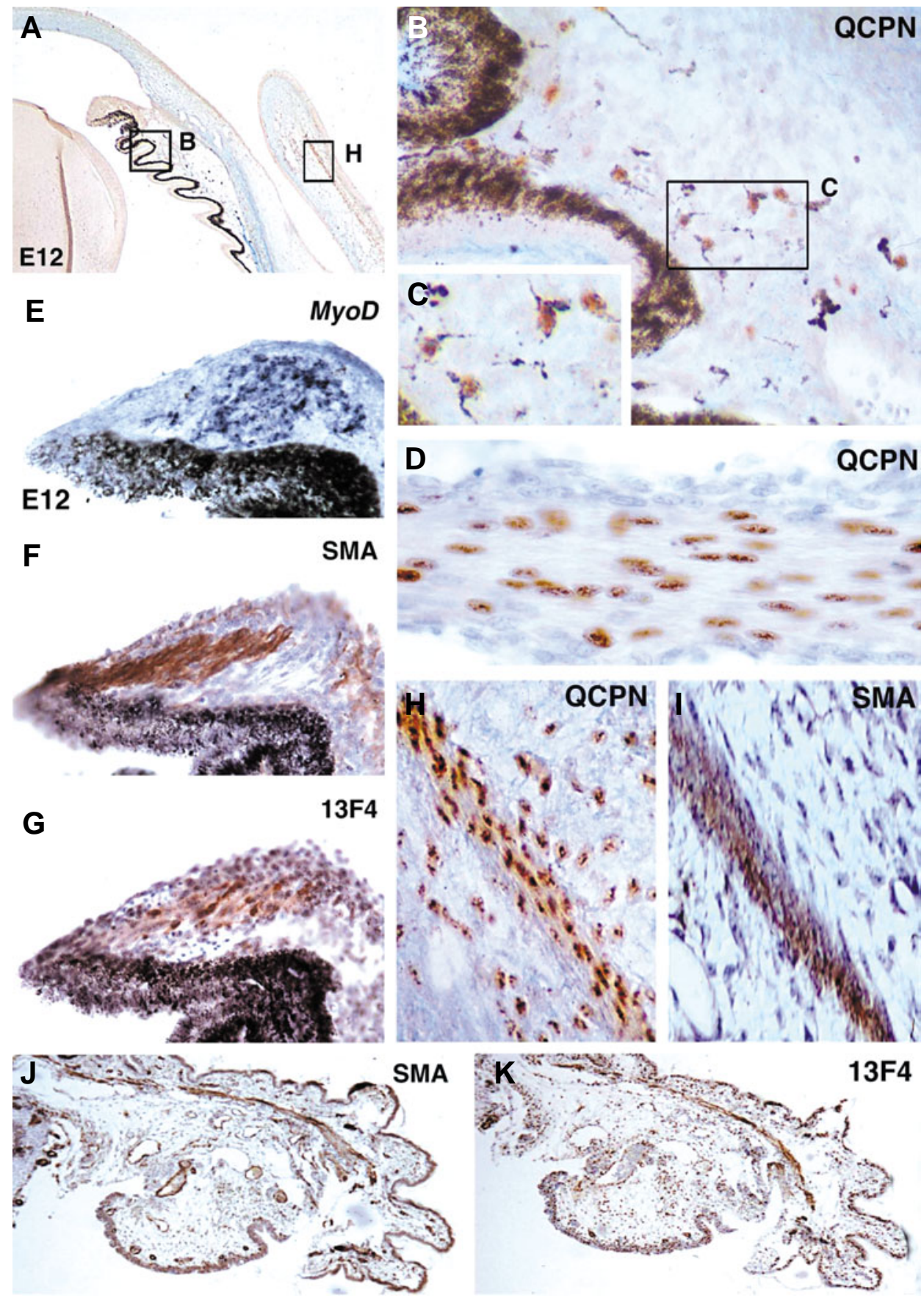

Fig. 5. Pigment and muscle fates of neural crest cells in the anterior segment of the eye. (A) Frontal section of the anterior chamber taken from an E12-old chick embryo engrafted with metencephalic neural crest at the 5ss. (B) In the ciliary processes, the mesenchymal pigmented cells are of quail origin (QCPN+) (C), while the pigmented epithelium belongs to the host. (D) Longitudinal section of iridial muscle fibers in which myonuclei are quail $(Q C P N+)$. (E) In the iridial stroma, a subset of crest-derived cells express the myogenic factor, MyoD. MyoD transcript detection is partly correlated with the accumulation of either the smooth-muscle actin protein (SMA) (F) and/or a differentiating muscle cell-related antigen (13F4 immunolabelling) (G). (H) In the lower eyelid, quail cells detected by QCPN Mab form the palpebral muscle consisting of smooth muscle cells (I) at this stage. At the end of incubation (i.e. E21), the plapebral muscle is a combination of smooth muscle-( $\mathbf{J})$ and striated muscle-type cells (K).

bulges of the pigmented retinal epithelium are involved in inserting the iridial muscle fibers.

We also show here that neural crest cells evenly compose iridial stroma. At mid-incubation, the crest-derived stroma encompasses discrete domains characterized by i) the expression of the myogenic factor $M y O D$ at the periphery, ii) the accumulation of smooth muscle actin expanding from the periphery towards the pupillar margin and iii) the expression of the differentiating myoblast antigen 13F4, superficially. For long, the coexistence of a smooth and striated musculature in the iris has been interpreted as resulting from distinct origins (see Gabella and Clarke, 1983 and references therein). Re-addressed by the use of quail-chick chimeras, ultrastructural studies yielded evidence that neural crest cells, which are responsible for the differentiation of dilatator (i.e. radial and oblique muscular

mesenchymal cells. This question has long been a matter of dispute and recently re-addressed by Barrio-Asensio and coworkers (Barrio-Asensio et al., 2002). Whilst re-evaluating the structure of the ciliary muscle, the authors suggested that pigmented cells arose from the delamination of the outer pigmented epithelium. This assumption based on a descriptive account also led to the confusing view that the pigmented ciliary process could give rise to the internal portion of ciliary muscle meaning that retina could yield smooth muscle cells. By using chimeras, we demonstrate here the crest origin of the pigmented cells infiltrating the ciliary region. However, due to their intimate connection, we cannot rule out that components) and sphincter (i.e. circumferential component) muscles, are able to generate both musculatures (Nakano and Nakamura, 1985). Dissecting the fate of iridial musculature in postnatal chicken until adulthood, Scapolo and coworkers provided a refined and extensive analysis that fully documented the differentiation of iridial muscle fibers according to their histochemical, metabolic and functional traits (Scapolo et al., 1988). Overall, these observations underline that, to a large extent, mesectodermal-derived myogenesis shares similarities with that of mesodermal origin. These similarities are consistent with the myogenic capacity of cephalic neural crest cells that have 
been described as myonucleus donor cells for the skeletal musculature of the jaw (Le Lièvre, 1976).

It has been established that the anterior optic chamber development is under the leading control of the lens (GenisGalvez, 1966). The lenticular vesicle, the morphogenesis of which likely results from posterior retinal cues, in turn seems to specify inner iridial and folded ciliary epithelia by both a prolonged contact inhibition and gradient-dependent influences from the retina (Coulombre and Coulombre, 1964; Stroeva, 1964). However, while being early committed into a differentiated structure, the iridial epithelium keeps a certain amount of plasticity until being able to dedifferentiate and restore the lens morphogenesis from the bulge of its pupillar margin (see Scheib, 1963 for a review); the completion of such a regenerating process is potentiated in newt compared to higher vertebrates. Supporting lens regeneration, a molecular cascade initiated by both Shh and Ihh pathways has recently highlighted this unique mechanism of retinal transdifferentiation in amphibians (Tsonis etal., 2004). By contrast, in chick, Shh signalling is essentially involved in retinal cell fate decision and confers a pigment-cell-differentiating bias rather than a neural-type fate to the retinal neuroepithelium (Zhang and Yang, 2001). These observations substantiate the influence of the local signalling environment on the specification of the epithelial components of the anterior optic chamber.

It turns out that environmental cues also locally coordinate the differentiation of their mesenchymal components. In this respect, $B m p$ expression from the inner ciliary epithelium is a crucial signalling for the development of the ciliary body, the develoment of which is thwarted by the production of the Bmp antagonist, Noggin, from the pigmented retinal epithelium (Zhao et al., 2002). If a source of Noggin is ectopically activates from the lens, the formation of the ciliary epithelium ceases and, as a consequence, the domain of neural retina is allowed to expand anteriorly. Moreover,

\section{TABLE 1}

\section{ORIGIN OF THE AVIAN OCULAR AND PERIOCULAR STRUCTURES}

Superficial epithelium

\begin{tabular}{|c|c|c|c|}
\hline Ectoderm & Neural crest & Mesoderm & Neural plate \\
\hline Corneal epithelium & $\begin{array}{l}\text { Corneal stroma } \\
\text { and endothelium }\end{array}$ & $\begin{array}{l}\text { Blood vessel } \\
\text { endothelium }\end{array}$ & $\begin{array}{l}\text { Iridial epithelium } \\
\text { and lamella }\end{array}$ \\
\hline Lens & $\begin{array}{l}\text { Iridial stroma } \\
\text { and muscles }\end{array}$ & $\begin{array}{l}\text { Myofibers of extra } \\
\text { ocular muscles }\end{array}$ & $\begin{array}{l}\text { Pigmental and } \\
\text { sensory retinae }\end{array}$ \\
\hline \multirow[t]{13}{*}{ Eyelid epithelia } & Ciliary muscles & & \\
\hline & Mesenchyme of ciliary & & \\
\hline & corpus and process & & \\
\hline & Wall of Schlemm's canal & & \\
\hline & Sclero-corneal limbus & & \\
\hline & Sclerotic ossicles & & \\
\hline & Choroid membrane & & \\
\hline & Sclerotic cartilage & & \\
\hline & $\begin{array}{l}\text { Muscles and mesenchyme } \\
\text { of eyelids and } \\
\text { nictitating membrane }\end{array}$ & & \\
\hline & $\begin{array}{l}\text { Mesenchyme of } \\
\text { lacrimal gland }\end{array}$ & & \\
\hline & $\begin{array}{l}\text { Connective tissue of } \\
\text { extraocular muscles }\end{array}$ & & \\
\hline & $\begin{array}{l}\text { Pericytes of ocular } \\
\text { blood vessels }\end{array}$ & & \\
\hline & $\begin{array}{l}\text { Frontal, lacrymal, } \\
\text { ethmoid, maxilla, } \\
\text { zygomatic bones }\end{array}$ & & \\
\hline
\end{tabular}

the myogenic differentiation of the iridial stromal cells is drastically reduced (Zhao et al., 2002). Consistent with a crucial role of Tgf $\beta$ superfamily antagonists in this process, Follistatin, which is expressed by the periocular mesenchyme (Feijen, et al., 1994; Darland et al.,1995; Verschuren et al., 1995), has been shown to orchestrate the transition from smooth-to-striated muscle in chick iridial stroma (Link and Nishi, 1997; 1998). By contrast, in the presence of an excess of Activin A that binds Follistatin, the accumulation of «striated» myosin heavy chains stops and, in turn, the development of smooth muscle characters is stimulated (Link and Nishi, 1998).

Another focus of neural crest-derived myogenesis concerns eyelids. From E6, we show that the accumulation of crest-derived mesenchyme at the lateral margin of the optic cup promotes and supports the outgrowth of ectodermal appendages fated to form the nictitating membrane and the eyelids. To date, little is known about the development of these structures. According to recent data, notable is the fact that eyelid mesenchyme relies on Egf signalling since the dominant mutation of its receptor, Egfr, chiefly hampers eyelid formation (Du et al., 2004). In addition, that the craniofacial skeleton and periocular structures (i.e. eyelids and nictitating membrane) share a common mesectodermal origin has been recently strengthened by functional analyses of Osrgenes (Lan et al., 2004). Encoding a transcription factor akin to the Drosophila odd-skipped, the Osr2 gene, if mutated, primarily affects the morphogenesis of the palatal shelf and likely operates through mesenchymal-epithelial interactions that imply Tgfß3 alteration in palatal epithelium. Surprisingly, this mutation also results in the loss of eyelid along with conspicuous corneal defects (Lan et al., 2004). Besides, using transgenic aproach, Dean and coworkers have recently shown that the morphogen $B m p 7$ is highly expressed in eyelid mesenchyme (Dean et al., 2004). As evoked before, given the involvement of TgfB family members and their respective antagonists in specifying the anterior eye segment, it is tempting to hypothesize that $B m p 7$ could partly determine the fate of neural crest cells and/or regulate their myogenic potential at this level. In this respect, investigating the neural crest-derived myogenic processes that take place in subectodermal location could possibly enlighten pathologies in human that relate to facial myotonic deficiencies.

As a tribute to the quail-chick chimera model, the interspecific combination has enabled a tremendous stride in the knowledge on one of the most refined structures of the vertebrate head. In this respect, the variety of cephalic neural crest-derived phenotypes discovered in the intra- and peri-ocular region accounts for the astonishing ability of the mesectodermal cells to fit and fine tune their differentiation to microenvironmental requirements. Further characterizations of the molecular pathways that govern neural crest cell commitment in these processes will provide novel insights into epithelio-mesenchymal cross-talks involved in eye development.

\section{Materials and Methods}

\section{Microsurgery}

Experiments were carried out on quail and chick embryos at 5-6 somites stage (5-6ss, i.e., 30 hours of incubation at $38^{\circ} \mathrm{C}$; stage 8 of Hamburger and Hamilton, 1951; HH9) according to techniques previously described (Teillet et al., 1999). The fate map of the cephalic neural primordium established by Grapin-Botton et al. (1995) served as a reference to determine the 
presumptive level of the cephalic neural fold extending from the diencephalon down to the first rhombomere $r 1$ (Fig. 1A).

\section{Embryo processing}

Immunodetection of graft-derived quail cells on either whole-mount preparations or paraffin sections were performed by using either QCPN monoclonal antibody (QCPN Mab; Hybridoma bank developmental studies) specific for a quail nuclear antigenic determinant, 1A4 Mab (Sigma), specific for smooth muscle actin (SMA) antigen, or 13F4 Mab (Hybridoma bank developmental studies), specific for differentiating muscle cells (Rong et al., 1987). Using a horseradish peroxidase (HRP)-linked Ab (Southern Biotechnology Associates Inc., Birmingham) as the secondary Ab. The specific immunolabelling was evidenced by 3-3'-diaminobenzidine tetra-hydrochloride (DAB), followed by hydrogen peroxide. Protocols for immunocytochemistry were performed as previously described (Chédotal et al., 1995; Creuzet et al., 2002). MyoD transcript detection was performed using the in situ hybridization technique previously described (Duprez et al., 1998; Etchevers et al., 1999).

For older specimens (from embryonic day 12, E12), quail cells were detected by the classic Feulgen-Rossenbeck histochemical staining for DNA on paraffin sections. Alternatively, QCPN immunodetection was also performed but slightly adapted as follows. After rehydratation, sections were heated for $10 \mathrm{~min}$ in a micro-wave oven $(700 \mathrm{~W})$ in a solution of Citric Acid $0.18 \mathrm{mM}$ and Sodium Citrate $0.82 \mathrm{mM}$. Sections were then allowed to cool for $45 \mathrm{~min}$ and rinsed in PBS prior to proceed to incubation with Abs

\section{Acknowledgements}

The authors thank S. Gournet, F. Beaujean and M. Fromaget for the illustrations. Work in the authors' laboratory is supported by the Centre National de la Recherche Scientifique, Institut National de la Santé et de la Recherche Médicale and Association pour la Recherche contre le Cancer. $S$. $C$. is a recipient of a fellowship from Fondation Lefoulon-Delalande.

\section{References}

ARENDT, D. (2003). Evolution of eyes and photoreceptor cell types. Int. J. Dev. Biol. 47: 563-571.

BARRIO-ASENSIO C., MURILLO-GONZÁLEZ, J., PEÑA-MELIÁN, A. AND PUERTA-FONOLLÁ, J. (1999). Immunocytochemical study on the triple origin of the sphincter iris in the chick embryo. Dev. Genes Evol. 209: 620-624.

BARRIO-ASENSIO C., PEÑA-MELIÁN, A., PUERTA-FONOLLÁ, J., VÁZQUEZOSORIO, T. and MURILLO-GONZÁLEZ, J. (2002). Ciliary muscle in avian is derived from mesenchymal and epithelial cells. Vision Res. 42: 1695-1699.

CHÉDOTAL, A., POURQUIÉ, O. and SOTELO, C. (1995). Initial tract formation in the brain of the chick embryo: selective expression of BEN/SC1/DM-GRASP cell adhesion molecule. Eur. J. Neurosci. 7: 198-212.

CIESIOLKA, M., DELVAEYE, M., VAN IMSCHOOT, G., VERSCHUERE, V., MCCREA, P., VAN ROY, F. and VLEMINCKX, K. (2004). P120 catenin is required for morphogenetic movements involved in the formation of the eyes and the craniofacial skeleton in Xenopus. J. Cell Biol. 117: 4325-4339.

COULOMBRE, A. J. and COULOMBRE, J. L. (1958). The role of the intraocular pressure in the development of thed chick eye.IV. corneal curvature. A.M.A. Arch. Ophthalmol. 59: 502-506.

COULOMBRE, A. J. and COULOMBRE, J. L. (1964). Embryonic mechanisms which shape and orient the lens. Anat. Rec. 148: 273.

COULY, G. F. and LE DOUARIN, N. M. (1985). Mapping of the early neural primordium in quail-chick chimeras. I. Developmental relationship between placodes, facial ectoderm and prosencephalon. Dev. Biol. 110: 423-439.

COULY, G. F. and LE DOUARIN, N. M. (1987). Mapping of the early neural primordium in quail-chick chimeras. II. The prosencephalic neural plate and neural folds: implications for the genesis of cephalic human congenital abnormalities. Dev. Biol. 120: 198-214.

COULY, G. F., COLTEY, P.M. and LE DOUARIN, N. M. (1992). The developmental fate of the cephalic mesoderm in quail-chic chimeras. Development114: 1-15.
COULY, G. F., COLTEY, P. M. and'LE DOUARIN, N. M. (1993). The triple origin of skull in higher vertebrates: a study in quail-chick chimeras. Development 117: 409-429.

COULY, G., CREUZET, S., BENNACEUR, S., VINCENT, C. and LE DOUARIN, N. M. (2002). Interactions between Hox-negative cephalic neural crest cells and the foregut endoderm in patterning the facial skeleton in the vertebrate head. Development 129: 1061-1073.

CREUZET, S., COULY, G., VINCENT, C. and LE DOUARIN, N. M. (2002). Negative effect of Hox gene expression on the development of the neural crest-derived facial skeleton. Development 129: 4301-4313.

CUARDOS, M. A., GARCIA-MARTIN, M., MARTIN, C. and RIOS, A. (1991) Haemopoietic phagocytes in the early differentiating avian retina. J. Anat. 177: 145-158.

CVEKL, A. and TAMM, E. R. (2004). Anterior eye development and ocular mesenchyme: new insights from mouse models and human diseases. Bioessays 26: $374-386$

DARLAND, D. C., LINK, B.A. and NISHI, R. (1995). Activin A and follistatin expression in developing targets of ciliary ganglion neurons suggest a role in regulating neuroransmitter phenotype. Neuron 15: 857-866.

DEAN, C., ITO, M., MAKARENKOVA, H. P., FABER, S. C. and LANG, R. A. (2004). Bmp7 regulates branching morphogenesis of the lacrimal gland by promoting mesenchymal proliferation and condensation. Development 131: 4155-4165.

DU X., TABETA, K., HOEBE, K., LIU, H., MANN, N., MUDD, S., CROZAT, K., SOVATH, S., GONG, X. and BEUTLER, B. (2004). Velvet, a dominant, egf mutation that causes wavy hair and defective eyelid development in mice. Genetics 166: 331-340.

DUPREZ D., FOURNIER-THIBAULT, C. and LE DOUARIN N. M. (1998). Sonic Hedgehog induce proliferation of committed skeletal muscle cells in the chick limb. Development 125: 495-505

ETCHEVERS, H. C., COULY, G., VINCENT, C. and LE DOUARIN, N. M. (1999). Anterior cephalic neural crest is required for forebrain viability. Development 126: 3533-3543.

FERNALD, R. D. (2000). Evolution of eyes. Curr. Op. Neurobiol. 10: 444-450.

FEIJEN, A., GOUMANS, M. J. and EIJND-VAN RAAIJ., J.M. (1994). Expression of activin subunits, activin receptors and follistatin in postimplantation mouse embryos suggests specific developmental functions for different activins. Development 120: 3621-3637.

GABELLA, G. and CLARKE, E. (1983). Embryonic development of the smooth and striated musculatures in the chick iris. Cell Tissue Res. 229: 37-59.

GARCIA-PORRERO J. A., COLVÉE, E. and OJEDA, J.L. (1984). The mechanism of cell death and phagocytosis in the early chick lens morphogenesis: a scanning electron microscopy and cytochemical study. Anat. Rec. 208: 123-136.

GENIS-GALVEZ, J. M. (1966). Role of lens in the morphogenesis of the iris and cornea. Nature 210: 209-210.

GEHRING, W.J. (2002). The genetic control of eye development and its implications for the evolution of the various eye-types. Int. J. Dev. Biol. 46: 65-73.

GRAPIN-BOTTON, A., BONNIN, M. A., MCNAUGHTON, L. A., KRUMLAUF, R and LE DOUARIN, N. M. (1995). Plasticity of transposed rhombomeres: Hox gene induction is correlated with phenotypic modifications. Development 121 2707-2721.

HAMBURGER, V. and HAMILTON, H. L. (1951). A series of normal stages in the development of chick embryo. J. Morphol. 88: 49-92.

HAY, E. D. (1980) Development of the vertebrate cornea. Int. Rev. Cytol. 63, 263 322.

JOHNSTON, M. C., NODEN, D. M., HAZELTON, R. D., COULOMBRE, R.D. and COULOMBRE, A. J. (1979). Origins of avian ocular and periocular tissues. Exp. Eye Res. 29: 27-43

KASTSCHENKO, N. (1888). Zur Entwicklungsgeschichte der Selachierembryos Anat. Anz. 3: 445-467.

LAN, Y., OVITT, C. E., CHO, E.-S., MALTBY, K. M., WANG, Q. and JIANG, R (2004). Odd-skipped related 2 (Osr2) encodes a key intrinsic regulator of secondary palate growth moprhogenesis. Development 131: 3207-3216.

LE DOUARIN, N. (1982). The Neura/Crest. Cambridge University Press, Cambridge

LE DOUARIN, N. M. and KALCHEIM, C. (1999). The Neural Crest(second edition) Cambridge University Press, New York. 
LE DOUARIN N. M., CREUZET S., COULY G. and DUPIN E. (2004). Neural crest cell plasticity and its limits. Development 131: 4637-4650.

LE LIÈVRE, C. (1974). Rôle des cellules mésectodermiques issues des crêtes neurales céphaliques dans la formation des arcs branchiaux et du squelette viscéral. J. Embryol. Exp. Morphol. 31: 453-477.

LE LIĖVRE C. (1976). Contribution des crêtes neurales à la génèse des structures céphaliques et cervicales chez les oiseaux. Doctoral thesis, University of Nantes.

LE LIÈVRE C. S. (1978). Participation of neural crest-derived cells in the genesis of the skull in birds. J. Embryol. Exp. Morphol. 47: 17-37.

LE LIÈVRE, C. S. and LE DOUARIN, N. M. (1975). Mesenchymal derivatives of the neural crest: analysis of chimaeric quail and chick embryos. J. Embryol. Exp. Morphol. 34: 125-154.

LINK, B.A. and NISHI, R. (1997). Oppposing effects of activin A and follistatin on developing skeletal muscle cells. Exp. Cell Res. 233: 350-362.

LINK, B.A. and NISHI, R. (1998). Development of the avian iris and ciliary body: the role of activin and follistatin in coordination of the smooth-to-striated muscle transition. Dev. Biol. 199: 226-234.

LWIGALE, P.Y., CONRAD, G.W. and BRONNER-FRASER, M. (2004). Graded potential of neural crest to form cornea, sensory neurons and cartilage along the rostrocaudal axis. Development 131: 1979-1991.

NAKANO, K. E. and NAKAMURA, H. (1985). Origin of the irideal striated muscle in birds. J. Embryol. Exp. Morph. 88: 1-13.

NODEN, D. M. (1983). The role of the neural crest in patterning of avian cranial skeletal, connective and muscle tissues. Dev. Biol. 96: 144-165.

PLATT, J. B. (1893). Ectodermic origin of the cartilage of the head. Anat. Anz. 8: 506-509.
RONG, P. M., ZILLER, C., PEÑA-MELIÁN, A. and LE DOUARIN, N. M. (1987). A monoclonal antibody specific for avian early myogenic cells and differentiated muscle. Dev. Biol. 122: 249-255.

SCAPOLO, P.A., PEIRONE, S.M., FILOFGAMO, G. and VEGETTI, A. (1988). Histochemical, immunochemical and ultrastructural observations on the iris muscles of Gallus gallus. Anat. Rec. 221: 687-699.

SCHEIB, D. (1963). Recherches récentes sur la régénération du cristallin chez les Vertébrés. Evolution du problème entre 1931 et 1963. Ergebn. Anat. EntwGesch. 38: 47-114.

STROEVA, O. G. (1967).'The correlation of the processes of proliferation and determination in the morphogenesis of iris and ciliary body in rats. J. Embryol. Exp. Morph. 18: 269-287.

TEILLET, M.-A., ZILLER, C. and LE DOUARIN, N. M. (1999). Quail-chick chimeras. In Molecular Embryology Methods and Protocols. Series: Methods in Molecular Biology (ed P.T. Sharpe and I. Mason), vol. 97, pp. 305-318. Totowa, N.J. USA: Humana Press Inc.

TSONIS P. A., VERGARA, M. N., SPENCE, J. R., MADHAVAN, M., KRAMER, E. L., CALL, M. K., SANTIAGO, W. G., VALLANCE, J. E., ROBBINS, D. J. and DEL RIO-TSONIS, K. (2004). A novel role of the hedgehog pathway in lens regeneration. Dev. Biol. 267: 450-461.

VERSCHUREN, K., DEWULF, N., GOUMANS, M.-J., LONNOY, O., FEIJEN, A., GRIMSBY, S., SPIEGLE, K. V., DIJKE, P., MOREN, A., VANCHEEUWIJCK, P., HELDIN, C.-H., MIYAZONO, K., MUMMERY, C., EIJNDEN VAN RAAIJ, J. and HUYLEBROECK, D. (1995). Expression of type I and type IB receptors for activin in midgestation mouse embryos suggests distinct functions in organogenesis. Mech. Dev. 52: 109-123.

ZHANG, X. M. and YANG, X. J. (2001). Temporal and spatial effects of sonic hedgehog signaling in chick eye morphogenesis. Dev. Biol. 233: 271-290.

ZHAO S., CHEN, Q., HUNG, F.-C. and OVERBEEK, P. A. (2002). BMP signaling is required for development of the ciliary body. Development 129: 4435-4442. 